\title{
Penerapan Metode Simple Additive Weighting (SAW) Dalam Penentuan Jenis Mobil Honda Yang Paling Diminati
}

\author{
Muchamad Ridwan ${ }^{1}$, Ahmad Setiadi ${ }^{2}$, Norma Yunita ${ }^{3}$, Siti Marlina ${ }^{4}$ \\ ${ }^{1}$ STMIK Nusa Mandiri \\ E-mail : ridwansamudra4@gmail.com \\ ${ }^{2}$ Universitas Bina Sarana Informatika \\ E-mail : ahmad.ams@bsi.ac.id \\ ${ }^{3}$ Universitas Bina Sarana Informatika \\ E-mail : norma.nyt@bsi.ac.id \\ ${ }^{4}$ STMIK Nusa Mandiri \\ E-mail : siti.smr@nusamandiri.ac.id
}

\begin{abstract}
Cara Sitasi: Ridwan, M., Setiadi, A., Yunita, N., \& Marlina, S. (2019). Penerapan Metode Simple Additive Weighting (SAW) Dalam Penentuan Jenis Mobil Honda Yang Paling Diminati. Paradigma - Jurnal Komputer dan Informatika, 21(2), 193-196. doi:10.31294/p.v21i2.6560
\end{abstract}

\begin{abstract}
For some people, car is no longer a luxury item that is difficult to obtain. Cars are one of the means of effective and efficient daily transportation. The specifications of each Honda car offered at PT Mitrausaha Gentaniaga Puri are very diverse and have advantages and disadvantages in terms of price, fuel consumption, cylinder content, fuel tank capacity, passenger capacity, and Other features. This makes the prospective buyers of Honda cars difficult to determine for themselves which car suits his needs. One method of decision support system that can be used in the Honda car selection at PT Mitrausaha Gentaniaga Puri is the Simple Additive Weighting (SAW) method. The concept of this method is to look for the weighted summation of the performance rating on each alternative of all attributes. An alternative with the largest value is the final result obtained to be used as a consideration for prospective buyers of Honda cars at PT Mitrausaha Gentaniaga Puri and the cars in demand are Mobilio, BRV, and CRV.
\end{abstract}

Keywords: Car, Decision Support System, Simple Additive Weighting

\section{PENDAHULUAN}

Mobil adalah bagian yang menghasilkan tenaga yang diperlukan untuk menggerakan mobil adalah mesin, sebagian besar yang digunakan pada mobil adalah model torak dan model pembakaran dalam, dimana model pembakaran dalam dapat dibagi dalam: motor bensin yang mana pencampuran udara dan bensin dilakukan dalam karburator dan dilakukan ke dalam silinder, campuran ini dimampatkan oleh torak dan dibakar untuk memperoleh tenaga dan kedua: motor diesel yang mana hanya udara saja yang dihisap ke dalam silinder, dengan menggunakan pengabut (injeksi bahan bakar) memungkinkan terjadinya pembakaran dan pengembangan (ekspansi) untuk menghasilkan tenaga (Daryanto, 2014)

Bagi sebagian masyarakat besar mobil bukan lagi merupakan suatu barang mewah yang sulit didapatkan. Mobil menjadi salah satu sarana transportasi sehari-hari yang efektif dan efisien.
Mobil pun sudah termasuk dalam kebutuhan pokok karena dapat membantu dalam beraktivitas khususnya bekerja.

Di Indonesia ada banyak merek mobil yang bersaing di bidang otomotif seperti Toyota, Mazda, Mitsubishi, Porsche dan masih banyak lagi. Honda menjadi salah satu dari beberapa merek yang ikut bersaing di bidang otomotif. Hal ini dapat dilihat dari data statistik GAIKINDO (Gabungan Industri Kendaraan Bermotor Indonesia) yang menunjukkan bahwa Honda selalu menempati urutan 3 besar penjualan unit mobil terbanyak pada setiap tahunnya. Volume penjualan mobil Honda pada bulan Januari hingga Maret 2019 sebanyak 28.845 unit $(11,4 \%)$. Sedangkan tahun 2016 sebanyak 199.364 unit (18,8\%), tahun 2017 sebanyak 186.859 unit $(17,3 \%)$ dan tahun 2018 sebanyak 162.163 unit $(14,1 \%)$ (Gaikindo.or.id, 2019)

Honda mempunyai bermacam-macam produk seperti HRV, CRV, Mobilio, BRV, Civic, Brio dan masih banyak lagi. Selain banyaknya macam-macam 
pilihan produk di atas, harga mobil, isi silinder, konsumsi bahan bakar, kapasitas tangki bahan bakar dan kapasitas penumpang dapat memberikan rekomendasi mobil Honda yang membantu customer atau calon pembeli untuk menentukan pilihan sesuai kebutuhan.

Pengambilan keputusan merupakan sesuatu yang akan selalu dihadapi oleh manusia. Keputusan yang diambil biasanya karena ada pertimbangan tertentu atau atas dasar logika, ada alternatif terbaik dari beberapa alternatif yang harus dipilih, dan ada tujuan yang harus dicapai. Keputusan merupakan hasil pemikiran berupa pemilihan satu diantara beberapa alternatif yang dapat digunakan untuk memecahkan masalah yang dihadapi (Pratiwi, 2016) Sistem Pendukung Keputusan yaitu sebagai suatu informasi berbasis komputer yang menghasilkan berbagai alternatif keputusan untuk membantu manajemen dalam menangani berbagai permasalahan yang terstruktur maupun tidak terstruktur dengan menggunakan data dan model (Nofriyansyah \& Sarjon, 2017)

Metode yang digunakan dalam penentuan jenis Mobil Honda pada PT Mitrausaha Gentaniaga Puri adalah Simple Additive Weighting (SAW). Dimana metode ini dapat membantu dalam pengambilan keputusan suatu kasus, akan tetapi perhitungan dengan menggunakan metode SAW ini hanya menghasilkan nilai terbesar yang akan terpilih sebagai alternatif terbaik. Metode Simple Additive Weighting (SAW) membantu pengambilan keputusan memilih sebuah alternatif yang memberikan hasil paling mendekati tujuannya. Tujuan dari penelitian ini yaitu untuk membantu customer dalam merekomendasikan mobil Honda yang sesuai dengan kebutuhan.

Penelitian ini akan membahas sistem pendukung keputusan dengan menggunakan metode Simple Additive Weighting (SAW). Metode ini dipilih karena mampu menyelesaikan data terbaik karena dilakukan dengan mencari nilai bobot untuk setiap atribut, seperti Kualitas Kerja, Integritas, Komitmen, Disiplin, Kerjasama, Kepemimpinan, Inovasi, dan Komunikasi. Dengan dilakukannya proses perangkingan yang akan menentukan alternatif yang optimal yaitu pemilihan Pegawai berprestasi. Tentunya proses ini dapat membantu Komisi Pemilihan Umum Kabupaten Bogor dalam melakukan proses penilaian kepada Pegawai berprestasi. (Yesni, 2018)

Untuk menentukan karyawan yang terbaik maka diperlukan penilaian dari kriteria- kriteria yang telah ditentukan. Untuk mendapatkan kriteria yang dijadikan sebagai acuan bisa melihat dari jurnal yang sudah ada seperti pada Penentuan Karyawan Terbaik Dengan Metode Simple Additive Weighting (PDAM Tirta Silaupiasa) karya Mahrizal Masri, memilih kriteria berdasarkan kualitas kerja, disiplin, semangat kerja, dan kerjasama. Sedangkan pada jurnal Sistem Pendukung Keputusan Pemilihan
Pegawai Terbaik PT Pegadaian Jakarta Dengan Metode Simple Additive Weighting karya Aulia Fitriah memilih kriterianya berdasarkan kepemimpinan, efektitas produk, fokus pelanggan, fokus tenaga kerja, keuangan dan pasar, inovatif, nilai moral tinggi, terampil, adi layanan dan nuansa citra. (Pamungkas, 2019)

\section{METODOLOGI PENELITIAN}

\section{Metode Pengumpulan Data}

Metode pengumpulan data yang dilakukan peneliti dibagi menjadi dua cara,

yaitu :

1. Melakukan observasi langsung, wawancara untuk mendapatkan data primer, dan membaca jurnal-jurnal penelitian yang relevan.

2. Data sekunder yang berasal dari mengumpulkan dan mengidentifikasi serta mengolah data tertulis berbentuk buku-buku yang berkaitan dengan penelitian.

\section{Populasi dan Sampel}

Populasi adalah wilayah generalisasi yang terdiri atas: obyek/subyek yang mempunyai kualitas dan karakteristik tertentu yang ditetapkan oleh peneliti untuk dipelajari dan kemudian ditarik kesimpulannya (Sugiyono, 2015). Dalam penelitian ini, peneliti melakukan observasi dan wawancara langsung kepada bagian Kepala Marketing PT Mitrausaha Gentaniaga Puri. Populasi akan diambil dari customer yang membeli mobil pada bulan Juni 2019.

Sampel adalah bagian dari jumlah dan karakteristik yang dimiliki oleh populasi tersebut (Sugiyono, 2015). Dari populasi tersebut akan diambil 43 customer untuk dijadikan sampel dalam penilaian mobil Honda

\section{Metode Analisis Data}

Analisa data merupakan bagian terpenting dalam metodologi penelitian ilmiah, dikarenakan dengan melakukan analisis data tersebut dapat diberi arti dan makna yang berguna dalam suatu penyelesaian masalah. Metode Simple Additive Weighting (SAW) merupakan metode penjumlahan bobot dari kinerja setiap obyek-obyek yang berbeda dan memiliki kesempatan yang sama pada semua kriteria yang dimiliki (Pratiwi, 2016)

\section{Penentuan Kriteria Metode Simple Additive Weighting}

Untuk melakukan pengambilan keputusan ini terdapat obyek, kriteria dan alternatif. Berikut kriteria-kriteria yang dibutuhkan untuk mengukur dan menilai apa aja yang masuk dalam kategori penentuan jenis mobil Honda yang yang paling diminati, antara lain: 
1. Harga

Indikator ini digunakan dalam penentuan jenis mobil Honda yang paling diminati berdasarkan rata-rata dari harga keseluruhan mobil Honda.

Tabel 1. Kriteria Harga

\begin{tabular}{cll}
\hline Harga(Rupiah) & Nilai & Bobot \\
\hline$<130-<=250$ Juta & 5 & 0,3 \\
\hline$>250-<=370$ Juta & 4 & 0,2 \\
\hline$>370-<=500$ Juta & 3 & 0,15 \\
\hline$>500-<=600$ Juta & 2 & 0.10 \\
\hline$>600-<=750$ Juta & 1 & 0,25 \\
\hline
\end{tabular}

Sumber : PT Mitrausaha Gentaniaga Puri (2019)

2. Konsumsi Bahan Bakar

Indikator ini digunakan dalam penentuan jenis mobil Honda yang paling diminati berdasarkan rata-rata dari konsumsi bahan bakar yang digunakan keseluruhan mobil Honda.

Tabel 2. Kriteria Konsumsi Bahan Bakar

\begin{tabular}{|c|c|c|}
\hline $\begin{array}{l}\text { Konsumsi Bahan } \\
\text { Bakar(Kpl) }\end{array}$ & Nilai & Bobot \\
\hline$>14$ & 5 & 0,3 \\
\hline $12-13$ & 4 & 0,2 \\
\hline 10-11 & 3 & 0,15 \\
\hline $8-9$ & 2 & 0.10 \\
\hline$<=7$ & 1 & 0,25 \\
\hline
\end{tabular}

Sumber : PT Mitrausaha Gentaniaga Puri (2019)

3. Isi Silinder

Indikator ini digunakan dalam penentuan jenis mobil Honda yang paling diminati berdasarkan rata-rata dari besarnya ukuran diameter silinder yang digunakan keseluruhan mobil Honda.

Tabel 3. Kriteria Isi Silinder

\begin{tabular}{ccl}
\hline Isi Silinder (CC) & Nilai & Bobot \\
\hline $2001-2500$ & 5 & 0,3 \\
\hline $1501-2000$ & 4 & 0,2 \\
\hline $1301-1500$ & 3 & 0,15 \\
\hline $1201-1300$ & 2 & 0.10 \\
\hline $1000-1200$ & 1 & 0,25 \\
\hline
\end{tabular}

Sumber : PT Mitrausaha Gentaniaga Puri (2019)

4. Kapasitas Tangki Bahan Bakar

Indikator ini digunakan dalam penentuan jenis mobil Honda yang paling diminati berdasarkan rata-rata dari besarnya ukuran tangki bahan bakar yang digunakan keseluruhan mobil Honda.

Tabel 4. Kriteria Kapasitas Tangki Bahan Bakar

\begin{tabular}{lll}
\hline $\begin{array}{l}\text { Kapasitas Tangki } \\
\text { Bahan Bakar }\end{array}$ & Nilai & Bobot \\
\hline 53 & 5 & 0,3 \\
\hline 50 & 4 & 0,2 \\
\hline 42 & 3 & 0,15 \\
\hline 40 & 2 & 0.10 \\
\hline 35 & 1 & 0,25
\end{tabular}

Sumber : PT Mitrausaha Gentaniaga Puri (2019)
5. Kapasitas Penumpang

Indikator ini digunakan dalam penentuan jenis mobil Honda yang paling diminati berdasarkan rata-rata dari besarnya ukuran kapasitas penumpang yang digunakan keseluruhan mobil Honda.

Tabel 5 Kriteria Kapasitas Penumpang

\begin{tabular}{lll}
\hline $\begin{array}{l}\text { Kapasitas } \\
\text { Penumpang }\end{array}$ & Nilai & Bobot \\
\hline 7 & 5 & 0,3 \\
\hline 6 & 4 & 0,2 \\
\hline 5 & 3 & 0,15 \\
\hline 4 & 2 & 0.10 \\
\hline 2 & 1 & 0,25 \\
\hline
\end{tabular}

Sumber : PT Mitrausaha Gentaniaga Puri (2019)

\section{HASIL DAN PEMBAHASAN}

\section{Membuat Matriks Keputusan Berdasarkan Kriteria (Ci)}

Nilai dari hasil table kecocokan diatas kemudian dibuat kedalam bentuk matriks sebagai berikut:

$$
X=\left[\begin{array}{lllll}
1 & 1 & 0,8 & 1 & 1 \\
0,6 & 1 & 0,6 & 1 & 0,75 \\
0,75 & 0,75 & 1 & 1 & 1 \\
0,75 & 0,75 & 0,6 & 1 & 1 \\
0,75 & 1 & 0,8 & 1 & 1 \\
0,75 & 1 & 0,6 & 1 & 0,75
\end{array}\right]
$$

\section{Normalisasi Matriks}

Membuat normalisasi matriks berdasarkan persamaan yang disesuaikan dengan jenis atribut (atribut keuntungan maupun atribut biaya) sehingga diperoleh matriks ternormalisasi R sebagai berikut:

Tabel 6. Penentuan Benefit atau Cost

\begin{tabular}{llll}
\hline Kriteria & Benefit & Cost \\
\hline Harga & - & $\checkmark$ & \\
\hline Konsumsi Bahan Bakar & $\checkmark$ & - & \\
\hline Isi Silinder & $\checkmark$ & - & \\
\hline $\begin{array}{l}\text { Kapasitas Tangki Bahan } \\
\text { Bakar }\end{array}$ & $\checkmark$ & - & \\
\hline Kapasitas Penumpang & $\checkmark$ & - & \\
\hline
\end{tabular}

Sumber : Penelitian (2019)

\section{Menentukan Ranking}

Untuk mencari nilai dari masing-masing jenis mobil Honda yang paling diminati, selanjutnya menentukan ranking dengan menggunakan rumus sebagai berikut:

$$
\mathbf{V}_{\mathrm{i}}=\sum_{\mathbf{j}=1}^{\mathrm{n}} \mathbf{w}_{\mathbf{j}} \mathbf{r}_{\mathrm{ij}}
$$

Menentukan nilai V1 sampai dengan V6 adalah sebagai berikut: 


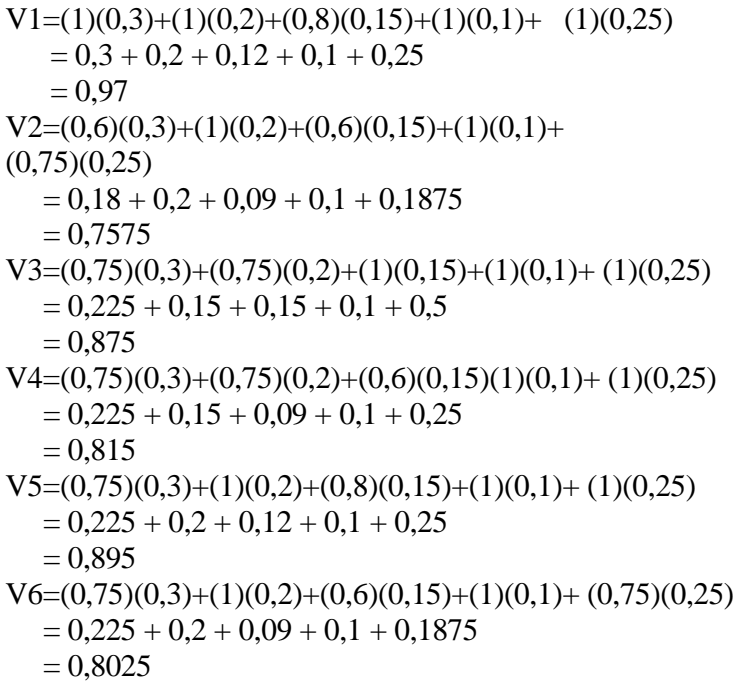

Adapun hasil dari perhitungan nilai V1 dari setiap jenis mobil Honda yang terpilih sebagai mobil Honda yang paling diminati maka dapat dibuat table penentuan ranking sebagai berikut:

Tabel 7. Penentuan Ranking

\begin{tabular}{llll}
\hline Kriteria & Benefit & Cost \\
\hline Harga & - & $\checkmark$ & \\
\hline Konsumsi Bahan Bakar & $\checkmark$ & - & \\
\hline Isi Silinder & $\checkmark$ & - & \\
\hline $\begin{array}{l}\text { Kapasitas Tangki Bahan } \\
\text { Bakar }\end{array}$ & $\checkmark$ & - & \\
\hline Kapasitas Penumpang & $\checkmark$ & - & \\
\hline Sumer : Penelitian (2019) & &
\end{tabular}

Sumber : Penelitian (2019)

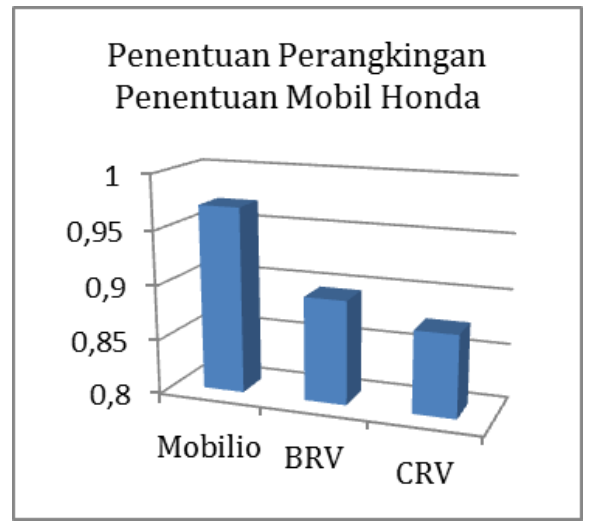

\section{Gambar 1. Grafik Perangkingan Penentuan Mobil} Honda

Dari penentuan jenis mobil Honda pada PT Mitrausaha Gentaniaga Puri dengan menggunakan metode Simple Additive Weighting (SAW) maka yang mendapat predikat terbaik pertama yaitu Mobilio dengan nilai 0,97 , kedua BRV dengan nilai 0,895 dan ketiga dengan nilai 0,875 .

\section{KESIMPULAN}

Berdasarkan maksud dan tujuan penelitian, pengolahan data, dan analisa yang telah dilakukan oleh penulis, maka dapat ditarik kesimpulan sebagai berikut: 1) Dengan penerapan metode Simple Additive Weighting (SAW) menghasilkan keputusan yang terbaik dalam penyelesaian dan perhitungan nilai-nilai kriteria yang dimiliki dalam penentuan jenis mobil Honda, sehingga diketahui hasil yang akurat dalam proses penentuan pemilihan jenis mobil Honda. 2) Dengan adanya penelitian ini, penulis memahami bagaimana prosedur-prosedur dalam memenuhi persyaratan dalam melakukan penentuan pemilihan jenis mobil Honda. 3) Dari hasil perhitungan menggunakan metode Simple Additive Weighting (SAW) dengan acuan kriteria harga, konsumsi bahan bakar, isi silinder, kapasitas tangki bahan bakar, dan kapasitas penumpang, maka jenis mobil Honda yang paling diminati di PT Mitrausaha Gentaniaga Puri adalah Honda Mobilio dengan nilai 0,97 dengan peringkat pertama, kemudian diperingkat kedua dengan nilai 0,895 yaitu Honda BRV. Dan diperingkat ketiga dengan nilai 0,875 yaitu Honda CRV.

\section{REFERENSI}

Daryanto. (2014). Dasar-Dasar Teknik Mobil. Jakarta: Bumi Aksara.

Gaikindo.or.id. (2019). Gabungan Indostri Kendaraan Bermotor Indonesia. Retrieved April 30, 2019, from https://www.gaikindo.or.id/indonesianautomobile-industry-data/

Nofriyansyah, D., \& Sarjon, D. (2017). Multi Critera Decision Making (MCDM) pada Sistem Pendukung Keputusan. (C. M. Sartono, Ed.) (1st ed.). Yogyakarta: Deepublish.

Pamungkas. (2019). Sistem Penunjang Keputusan Pemilihan Karyawan Terbaik Menggunakan Metode Simple Additve Weighting (SAW) Pada PT Ringkat Teknologi Muliatama Jakarta, 5(1), 71-77.

Pratiwi, H. (2016). Buku Ajar Sistem Pendukung Keputusan. (Invalindiant Candrawinata, Ed.) (1st ed.). Yogyakarta: Deepublish.

Sugiyono. (2015). METODE PENELITIAN Kuantitatif, Kualitatif, dan $R \& D$. (ALFABETA, Ed.). Bandung.

Yesni, M. (2018). Sistem pendukung keputusan pemilihan pegawai berprestasi di komisi pemilihan umum kabupaten bogor. Jurnal Teknik Komputer, 4(1), 66-73. 